\title{
Awareness of basic life support among medical students in Syria, Iraq and Jordan: a cross sectional study
}

\section{Mohammad Nour Shashaa}

University of Aleppo

Mohamad Shadi Alkarrash ( $\square$ Shadi.karrash2@gmail.com )

University of Aleppo

\section{Mohammad Nour Kitaz \\ University of Aleppo}

Roaa Rhayim

University of Aleppo

Mohammed Ismail

University of Aleppo

M. Ihsan Kaadan

Boston Medical Center

Hamzeh Koumakli

University of Albaath

Nour Alhisah

University of October 6 university

Ahmed Al-Haider

University of Al-Qadisiyah

Samer Al-salloum

Aleppo University Hospital

\section{Research Article}

Keywords: Basic life support, Awareness, Medical students, University, Cardiopulmonary resuscitation, Syria, Jordan, Iraq

Posted Date: June 4th, 2021

DOI: https://doi.org/10.21203/rs.3.rs-584155/v1

License: (c) (i) This work is licensed under a Creative Commons Attribution 4.0 International License.

Read Full License 


\section{Abstract}

Background: Sudden cardiac arrest is one of the most leading causes for death in all over the world. Basic life support (BLS) training rates vary worldwide, there is a general scarce in the number of Surveys which evaluate knowledge, and awareness about BLS in Middle Eastern countries students especially Jordan, Syria and Iraq. The purpose of this study is to evaluate the awareness of basic life support among medical students.

Methods: A Cross sectional web based questionnaire study was conducted in November 2020. The study included 2114 medical students in Syria, Iraq and Jordan. We evaluated BLS skills according to total mean score of correct answers. The participants were classified according to gender, residence, country, University, academic degree, and academic stage to study their effect on the participants' BLS knowledge. A chi-squared test was used to determine if there were differences between those who attended a basic life support course and those who did not.

Results: 1656 of the participants $(78.3 \%)$ stated that they did not attend a basic life support course. There was a significant difference between the participants from different countries where the mean score in Syria, Jordan and Iraq was $18.3,24.3$ and 18.8 respectively $(p<0.05)$. The participants were divided into 3 level according to total score; low (0-12), moderate (13-24) and high (25-37). In total, $18.3 \%, 72.8 \%$ and $8.9 \%$ of participants had high, intermediate and low level respectively.

Conclusion: The overall knowledge of basic life support among medical students is not adequate and need significant improvements. This study showed that an attendance a basic life support course previously had an effect on knowledge level. Hence, there is an urgent need to apply basic life support courses into the pre-clinical stage at universities.

\section{Background}

Sudden cardiac arrest is one of the most leading causes of death in all over the world. However, Basic life support (BLS) including cardiac pulmonary resuscitation (CPR) is the appropriate management. [1] BLS technique recognizing includes many signs; cardiac arrest, stroke, foreign body airway obstruction, heart attack and defibrillation with an automated external defibrillation (AED). [2] [3] Neonates and infants can also be seen with cardio- respiratory arrest [4]. Therefore, health care provider should know the differences in BLS algorithm.

BLS training rates differentiate worldwide, there is a general scarce in the number of Surveys which evaluates knowledge, and awareness about BLS in Middle Eastern countries students especially Jordan, Syria and Iraq. In a study evaluating knowledge and awareness towards CPR among university of Riyadh students in Saudi Arabia found that 31\% did not have any prior CPR skills knowledge. $85 \%$ of those with preceding knowledge felt that it was insufficient. Overall, $88 \%$ of students want to learn how to perform CPR. [5] Another Egyptian study from Al-Azhar medical schools showed that among all included students, 
only $27 \%$ had previously attended BLS course, and only $34.3 \%$ reported that they had completed a course before. [6]

Inadequate confidence in performing BLS has also been reported among medical students in Europe [7], and insufficient training among medical students in U.K and Poland has also been documented. [8][9]

There is a big shortage of emergency medical professionals in Syria, Iraq and Jordan, it is very essential to teach the student about BLS principles. This cross sectional study aims to assess the perceptions about BLS among Syrians, Jordanians and Iraqis medical students because there are no enough studies related to BLS has been reported from the three countries.

\section{Methods}

\section{Study design, setting and data collection:}

A cross sectional web based questionnaire study was conducted in November 2020. The study included six universities from Syria, ten universities from Iraq and six universities from Jordan. We distributed the questionnaire in all universities, including pre-clinical and clinical years, via official Universities groups on social media. The study was conducted through an electronic questionnaire due to COVID19 pandemic. The students read the purpose of the survey before answering the questionnaire, and the participation was voluntary and anonymous. The total number of participants was 2114 , and the power analysis was not performed.

\section{The survey:}

We designed a closed ended, electronic questionnaire depending on review of pertinent literature [6] [10] and the latest American Heart Association (AHA) guidelines for BLS. The survey was piloted on 20 students, which was easy to understand, except for one question of the second section for that have been deleted. The students in the pilot study were excluded from data analysis. The questionnaire included 4 sections. The first section collected demographic data (age, gender, country, residence, university, academic year, academic degree and attendance a BLS course previously). The second section consisted of 19 questions to assess the participants ' knowledge and awareness about BLS (i.e., assessment of airway, breathing, CPR technique, AED use and dealing with victims of drowning and choking). The third section consisted of 18 questions about indications of cardiopulmonary resuscitation, signs of successful CPR and suitable response in case of emergency situations. The latter section consisted of 5 questions about the participants' opinions of their ability to apply basic life support. We also inquired about importance of applying basic life support education in the first and second years in medical colleges. Firstly, the questionnaire was written in English. Afterwards, we translated it to Arabic because it is the local language. We reported the English version of the study in additional file 1. The dean of the faculty of medicine at Aleppo University approved the survey, which was compatible with the Declaration of Helsinki.

\section{Statistical analysis:}


Data analysis was done by using SPSS version 26. We gave each question (second and third section from questionnaire) one point and calculated the total score which was 37 . The participants were classified according to gender, residence, country, University, academic degree, and academic stage to study their effect on the participants' BLS knowledge. We performed descriptive statistics to calculate the number of participants (percent), mean of score, standard deviations, minimum and maximum value for each sub-group. Independent-samples T test and one-way ANOVA were used to evaluate and quantify the association between the categorical outcomes. A chi-squared test was used to determine if there were differences between those who attended BLS course and those who did not attend it regarding CPR skills. $\mathrm{P}<0.05$ was considered significant.

\section{Results}

\section{Demographic characteristics:}

A total of 2114 participants completed the questionnaire, 1204 of them were from Syria, 433 were from Jordan, 477 were from Iraq. 1174 (55.5\%) and 940 (44.5\%) of the participants were females and males respectively. $1223(58.3 \%)$ of the participants were in pre-clinical stage and $881(41.7 \%)$ were in clinical stage. We found that the majority of participants did not attend a BLS course (78.3\%). Table 1 demonstrates student demographics.

\section{BLS knowledge:}

When we compared the mean score between the sub-groups, we found that there was no significant difference in mean score among males (19.8) and females (19.5). In contrast to gender, there was a significant difference among the participants from different country where the mean score in Syria, Jordan and Iraq was $18.3,24.3$ and 18.8 respectively $(p<0.05)$. In addition, there was a significant difference among the participants according to their residence, University, academic degree, and academic stage. (Table 2)

The participants who attended BLS course had a higher mean score 21.6 in compare with who did not attend $19.1(p<0.05)$. (Table 2)

\section{CPR skills:}

We compared between the knowledge of the participants who attended previously BLS training and who did not attend a course especially in some domains of CPR (massage rate, massage location, and massage depth, massage/ventilation ratio). In comparison between those who underwent BLS training and those who did not undergo BLS training, $82.5 \%$ and $50.6 \%$ of them reported that they knew the pressure/ventilation ratio respectively. We found a significant difference between the two groups in all domains $(P<0.05)$. (Table 3$)$

The participants were divided into 3 level according to total score; low (0-12), moderate (13-24) and high (25-37). In total, $18.3 \%, 72.8 \%$ and $8.9 \%$ of participants had high, intermediate and low level respectively. (Fig. 1) 


\section{Perception of the medical students toward BLS:}

$36.2 \%$ of the participant were not confident of performing CPR and about $70.3 \%$ were uncomfortable to be in a situation that requires performing CPR. Moreover, about $59.1 \%$ of the student assessed themselves 5 or less in a self-assessment of mastery of Basic Life Support. (Table 4)

\section{Discussion}

It is important for all medical students to learn about BLS as they can face life-threatening emergencies in their daily life. The American Heart Association recommended that everyone should be given training of the BLS regardless of their study or specialization. [11] Recently, several publications have highlighted the deficiencies in BLS knowledge among medical students [12] [13]. We found that in our study, no student was able to answer all the questions correctly. However, Jordan has better results than Syria and Iraq in total. Jordan had a higher mean score (24.2) than Syria (18.3) and Iraq (18.9). In comparison between the three countries, $61 \%$ of Jordanian students have high level while $82.8 \%$ and $85.3 \%$ of Syrian and Iraqi students respectively have moderate level. This can be justified due to the lack of training centers in Syria and Iraq due to the internal crisis. Additionally, Jordan has a better education system. Regarding BLS training, the results showed that $21.7 \%$ of the participants stated that they had received BLS training, lower than reported in Oman (35.2\%), [13] Egypt (27\%), [6] Saudi Arabia (22.5\%) [14]. Conversely it was higher than reported in India (18.9\%) [10] and Pakistan (14.7\%) [15]. All health-care staff in the US were recommended to receive BLS training routinely since 1966. [16] In general, our study showed a lower percentage of trained medical students in comparison to other countries. Consequently, there is a necessity to train the medical students in BLS skills to bring Syria, Iraq and Jordan in line with international norms. The results showed that the gender had not an apparent effect on knowledge level. Similar result reported in Saudi Arabia [14] but another studies in France showed a difference between males and females [17]. In contrast to gender, the results showed that attendance a BLS course previously had significant effect on knowledge level. Similar results were reported from Oman, [13] United Kingdom, [18] Pakistan [15] and Thailand [19]. In this study, the numbers of participants who received training in BLS and had knowledge of CPR (massage rate, massage location, massage depth and massage/ventilation rate) were higher than those who did not receive training. Although about $72.8 \%$ of participants had an intermediate level, most of them (77\%) wanted to avoid/were uncomfortable and about (36.2\%) were not confident of CPR performing similarly to the findings that have been reported from India [10] and Europe. [20] A Syrian randomized controlled trial study revealed that peer-led training in BLS for medical students in pre-clinical years is sufficient in comparison with health professional-led training. [21] Consequently, it can be effectively performed in bad situations of crisis such as in Syria. Therefore, the individuals could be benefit from medical students to increase their BLS skills. When we asked the participants about BLS training, $82.8 \%$ of the participants agreed to apply BLS training during the first and second year of the university. Altintaş et al also showed that $75.6 \%$ of the participants stated that they could apply BLS confidently in real situations after receiving training. [22] According to Pande et al there is an increase in mean score of BLS knowledge from 3.42 to 7.42 one week after the BLS training attendance among first year medical students. [23] The knowledge of BLS may decrease in the 6 months 
following the training as seen in Winchana et al study. [19] Therefore, students should constantly review BLS principles continually and keep up to date with the latest guidelines. Regarding universities ranking, the results showed that universities in Jordan achieved the first six ranks, while there is only one Syrian university among the top 10 universities. (Table 5) We can explain that by good educational system in the Jordanian universities which exceed the universities of Iraq and Syria, depending on Webometrics Ranking of World Universities. [24] Finally, we encourage to benefit from different media (television, internet) to realize, emphasize and enhance the importance of BLS principles in our life because of their large audience as seen in a study from Saudi Arabia showed that the most common sources of CPR performing are television and movies. [25] Additionally, a well trained personnel programs via media will have a positive influence on public health for the society. The morbidity and mortality can be reduced by training medical students at an early stage that also enhance the student's confidence to face many emergency situations and act appropriately. To achieve this goal, the educational system should be developed by depend on American Heart Association (AHA) guidelines in the educational curriculum. Practical courses and training on mannequins is recommended to master the basics of BLS.

\section{Limitations}

The major limitation of this study was the data collection technique through the use of an online questionnaire distribution. We did not design practical tests to assess students' experiences. Another limitation was the heterogeneity of the participants among countries, where the number of students was the largest from Syria. Moreover, we did not include all universities in the three countries.

\section{Conclusion}

The results indicate that medical students' knowledge toward BLS is significant and requires more effort. In addition, this study showed that an attendance a BLS course had positive impact on knowledge level. Hence, there is an urgent need to apply BLS courses into the undergraduate curriculum, particularly in preclinical stage. In general, Jordan had better results than Syria and Iraq, indicating that more focus is needed to increase the level of knowledge among medical students in BLS skills to bring these countries in line with international norms.

\section{List Of Abbreviations}

BLS: basic life support; CPR: cardiac pulmonary resuscitation; AED: automated external defibrillation; AHA: American Heart Association; SPSS: statistical package for social sciences

\section{Declarations}

\section{Ethics approval and consent to participate}


Ethical approval has been granted by the dean of the Faculty of Medicine at Aleppo University. The consent was collected from participants as a part of the electronic form. (reference number 116)

\section{Consent for publication}

Not applicable; the study is anonymous.

\section{Availability of data and materials}

All data generated or analyzed during this study are included in this published article and its supplementary information files.

\section{Competing interests}

The authors declare that they have no competing interests.

\section{Funding}

There are no funding sources.

\section{Authors' contributions}

MNS: wrote the manuscript, contributed to project administration, study design, data interpretation MSA: conceived of the idea of the research, wrote the manuscript, reviewing the manuscript and corresponding author

MNK: data analysis, wrote the manuscript, data interpretation

RR and Ml: prepared the questionnaire and entering data

MIK: contributed to validation and reviewing the manuscript

HK, NA and AA: data collection, conducted the literature review

SA: approved, reviewed, and edited both the survey and the manuscript.

All authors read and approved the final manuscript.

\section{Acknowledgements}

We would like to thank Dr. Mohamed Bisher Zeina for sharing his expertise in statistics.

Collaboration Group:

Ahmad Farran, Manar Haddad 


\section{Authors' information}

${ }^{1}$ Faculty of Medicine, University of Aleppo, Aleppo, Syria

${ }^{2}$ Department of Medicine, Boston Medical Center, Boston, Massachusetts

${ }^{3}$ Department of Medicine, Boston University School of Medicine, Boston, Massachusetts

${ }^{4}$ Faculty of Medicine, University of Albaath, Homs, Syria

${ }^{5}$ Faculty of Medicine, University of October 6 university, Madaba, Jordan

${ }^{6}$ Faculty of Medicine, University of Al-Qadisiyah, Al-Qadisiyah, Iraq

${ }^{7}$ Emergency department, Aleppo University Hospital, Aleppo, Syria

\section{References}

1. Tipa RO, Bobirnac G. Importance of basic life support training for first and second year medical students-a personal statement-. Journal of medicine and life. 2010 Nov 15;3(4):465.

2. Almesned A, Almeman A, Alakhtar AM, AlAboudi AA, Alotaibi AZ, Al-Ghasham YA, Aldamegh MS. Basic life support knowledge of healthcare students and professionals in the Qassim University. International journal of health sciences. 2014 Apr;8(2):141.

3. Chandrasekaran S, Kumar S, Bhat SA. Awareness of basic life support among medical, dental, nursing students and doctors. Indian journal of Anaesthesia. 2010 Mar;54(2):121.

4. Zaheer H, Haque Z. Students' Corner-Awareness about BLS (CPR) among medical students: Status and requirements. JPMA. The Journal of the Pakistan Medical Association. 2009;59(1):57.

5. Al-Turki YA, Al-Fraih YS, Jalaly JB, Al-Maghlouth IA, Al-Rashoudi FH, Al-Otaibi AF, Al-Thnayan AA, Trabzoni Al, Al-Shaykh AS. Knowledge and attitudes towards cardiopulmonary resuscitation among university students in Riyadh, Saudi Arabia. Saudi med J. 2008 Sep 1;29(9):1306-9.

6. Ghanem E, Elgazar M, Oweda K, Tarek H, Assaf F, El-Husseny MW, Elgebaly A, Abushouk Al. Awareness of basic life support among Egyptian medical students; a cross-sectional study. Emergency. 2018;6(1).

7. Freund Y, Duchateau FX, Baker EC, Goulet H, Carreira S, Schmidt M, Riou B, Rouby JJ, Duguet A. Selfperception of knowledge and confidence in performing basic life support among medical students. European Journal of Emergency Medicine. 2013 Jun 1;20(3):193-6.

8. Mastoridis S, Shanmugarajah K, Kneebone R. Undergraduate education in trauma medicine: the students' verdict on current teaching. Medical teacher. $2011 \mathrm{Jul}$ 1;33(7):585-7. 
9. Chandrasekaran S, Kumar S, Bhat SA. Awareness of basic life support among medical, dental, nursing students and doctors. Indian journal of Anaesthesia. 2010 Mar;54(2):121.

10. Chowdari A, Niranjan GM, Dinesh B. A cross-sectional study on awareness and perception about basic life support/cardio-pulmonary resuscitation among undergraduate medical students from coastal South India. International Journal of Medicine and Public Health. 2013;3(3).

11. Cardiopulmonary resuscitation (CPR): first aid. https://www.mayoclinic.org/first-aid/first-aidcpr/basics/art-20056600 2018

12. Zaheer H, Haque Z. Students' Corner-Awareness about BLS (CPR) among medical students: Status and requirements. JPMA. The Journal of the Pakistan Medical Association. 2009;59(1):57.

13. Albadi S, Al-Hadi H, Nadar SK. Knowledge and Attitudes toward Basic Life Support among Medical Students in Oman. Indian Journal of Critical Care Medicine: Peer-reviewed, Official Publication of Indian Society of Critical Care Medicine. 2020 Jul;24(7):599.

14. Mansour A, Alsager AH, Alasqah A, Altamimi AS, Alsuhaibani A, Aljabr AA, AlDughaim Al. Student's Knowledge, Attitudes, and Practices Related to Cardiopulmonary Resuscitation at Qassim University, Saudi Arabia. Cureus. 2019 Nov;11(11).

15. Abbas A, Bukhari SI, Ahmad F. Knowledge of first aid and basic life support amongst medical students: a comparison between trained and un-trained students. JPMA. The Journal of the Pakistan Medical Association. 2011 Jun 1;61(6):613-6.

16. Roshana S, Batajoo KH, Piryani RM, Sharma MW. Basic life support: knowledge and attitude of medical/paramedical professionals. World journal of emergency medicine. 2012;3(2):141.

17. Freund Y, Duchateau FX, Baker EC, Goulet H, Carreira S, Schmidt M, Riou B, Rouby JJ, Duguet A. Selfperception of knowledge and confidence in performing basic life support among medical students. European Journal of Emergency Medicine. 2013 Jun 1;20(3):193-6.

18. Willmore RD, Veljanoski D, Ozdes F, Stephens B, Mooney J, Crumley SG, Doshi A, Davies P, Badhrinarayanan S, Day E, Tattam K. Do medical students studying in the United Kingdom have an adequate factual knowledge of basic life support?. World journal of emergency medicine. 2019;10(2):75.

19. Srivilaithon W, Amnuaypattanapon K, Limjindaporn C, Diskumpon N, Dasanadeba I, Daorattanachai K. Retention of Basic-Life-Support Knowledge and Skills in Second-Year Medical Students. Open Access Emergency Medicine: OAEM. 2020;12:211.

20. Freund Y, Duchateau FX, Baker EC, Goulet H, Carreira S, Schmidt M, Riou B, Rouby JJ, Duguet A. Selfperception of knowledge and confidence in performing basic life support among medical students. European Journal of Emergency Medicine. 2013 Jun 1;20(3):193-6. 
21. Abbas F, Sawaf B, Hanafi I, Hajeer MY, Zakaria MI, Abbas W, Alabdeh F, Ibrahim N. Peers versus professional training of basic life support in Syria: a randomized controlled trial. BMC medical education. 2018 Dec;18(1):1-9.

22. Altintas KH, Aslan D, Yildiz AN, Subasi N, Elçin M, Odabasi O, Bilir N, Sayek I. The evaluation of first aid and basic life support training for the first year university students. The Tohoku journal of experimental medicine. 2005;205(2):157-69.

23. Pande S, Pande S, Parate V, Pande S, Sukhsohale N. Evaluation of retention of knowledge and skills imparted to first-year medical students through basic life support training. Advances in physiology education. 2014 Mar;38(1):42 - 5.

24. Webometrics Ranking of World Universities. edition 2021.1.0 beta [Available from: https://www.webometrics.info/en/current_edition

25. Al-Turki YA, Al-Fraih YS, Jalaly JB, Al-Maghlouth IA, Al-Rashoudi FH, Al-Otaibi AF, et al. Knowledge and attitudes towards cardiopulmonary resuscitation among university students in Riyadh, Saudi Arabia. Saudi Med J. 2008;29(9): 1306-1309. Epub 2008/09/25. PubMed PMID: 18813417.

\section{Tables}

Table 1: Demographic characteristics of the participants. 


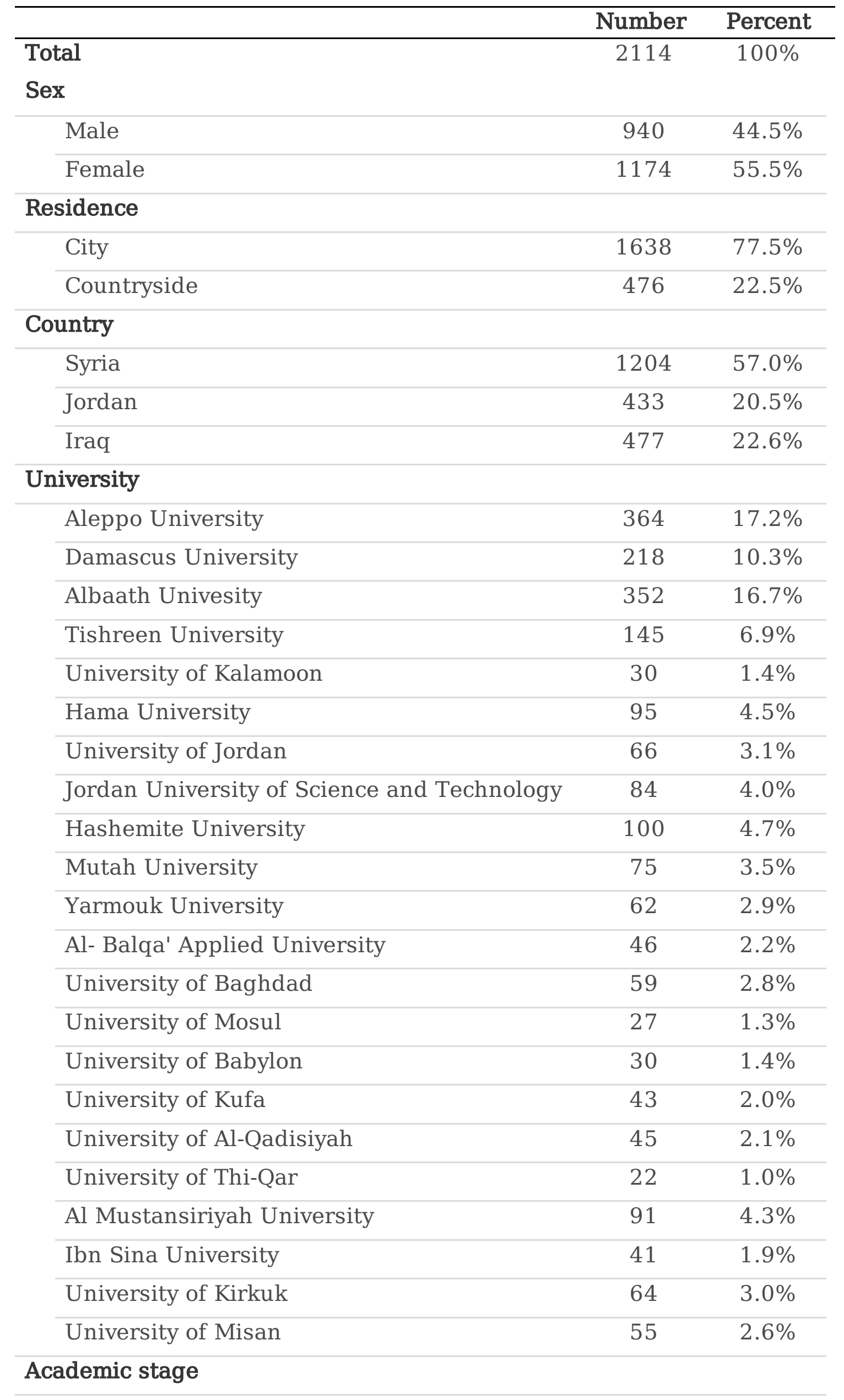




\begin{tabular}{lcc} 
Pre-clinical & 1233 & $58.3 \%$ \\
\hline Clinical & 881 & $41.7 \%$ \\
\hline Academic degree & & \\
\hline $60-69$ & 180 & $8.5 \%$ \\
\hline $0-79$ & 745 & $35.2 \%$ \\
\hline $80-89$ & 718 & $34.0 \%$ \\
\hline $90-100$ & 471 & $22.3 \%$ \\
\hline Have you attended BLS course previously? & & \\
\hline No & 1656 & $78.3 \%$ \\
\hline Yes & 458 & $21.7 \%$ \\
\hline
\end{tabular}

Table 2: Mean score of the students. 


\begin{tabular}{|c|c|c|c|c|c|}
\hline & Mean & SD & Minimum & Maximum & $\begin{array}{c}\mathrm{P}- \\
\text { value }\end{array}$ \\
\hline Total & 19.67 & 5.7 & 0 & 34 & \\
\hline Sex & & & & & $0.205^{a}$ \\
\hline Male & 19.8 & 6.1 & 0 & 34 & \\
\hline Female & 19.5 & 5.3 & 0 & 33 & \\
\hline Residence & & & & & $0.000^{a}$ \\
\hline City & 19.4 & 5.5 & 0 & 34 & \\
\hline Countryside & 20.7 & 6.2 & 1 & 34 & \\
\hline Country & & & & & $0.000^{b}$ \\
\hline Syria & 18.3 & 4.9 & 0 & 32 & \\
\hline Jordan & 24.3 & 6.6 & 3 & 34 & \\
\hline Iraq & 18.9 & 4.5 & 3 & 32 & \\
\hline University & & & & & $0.000^{b}$ \\
\hline University of Aleppo & 17.0 & 5.3 & 0 & 31 & \\
\hline Damascus University & 18.5 & 4.4 & 0 & 28 & \\
\hline Albaath University & 19.0 & 4.3 & 2 & 31 & \\
\hline Tishreen University & 18.2 & 5.5 & 2 & 32 & \\
\hline University of Kalamoon & 18.4 & 3.7 & 10 & 26 & \\
\hline Hama University & 20.2 & 3.9 & 10 & 30 & \\
\hline University of Jordan & 21.7 & 6.6 & 6 & 31 & \\
\hline $\begin{array}{l}\text { Jordan University of Science and } \\
\text { Technology }\end{array}$ & 23.6 & 7.7 & 6 & 33 & \\
\hline Hashemite University & 25.8 & 5.1 & 6 & 33 & \\
\hline Mutah University & 23.4 & 6.0 & 3 & 33 & \\
\hline Yarmouk University & 25.0 & 7.4 & 6 & 34 & \\
\hline Al- Balqa' Applied University & 26.4 & 6.2 & 9 & 34 & \\
\hline University of Baghdad & 20.8 & 3.6 & 14 & 30 & \\
\hline University of Mosul & 17.5 & 3.8 & 10 & 23 & \\
\hline University of Babylon & 18.7 & 3.7 & 10 & 26 & \\
\hline University of Kufa & 19.9 & 4.5 & 4 & 28 & \\
\hline University of Al-Qadisiyah & 20.9 & 4.5 & 11 & 32 & \\
\hline University of Thi-Qar & 21.1 & 3.6 & 17 & 31 & \\
\hline Al Mustansiriyah University & 17.1 & 4.1 & 6 & 25 & \\
\hline Ibn Sina University & 17.5 & 5.1 & 3 & 31 & \\
\hline University of Kirkuk & 19.0 & 3.7 & 10 & 30 & \\
\hline University of Misan & 18.5 & 5.3 & 3 & 32 & \\
\hline Academic stage & & & & & $0.000^{b}$ \\
\hline Pre-clinical & 18.8 & 6.3 & 0 & 34 & \\
\hline Clinical & 20.9 & 4.5 & 0 & 33 & \\
\hline Academic degree & & & & & $0.000^{b}$ \\
\hline $60-69$ & 17.7 & 5.0 & 0 & 30 & \\
\hline $70-79$ & 19.6 & 5.7 & 0 & 33 & \\
\hline
\end{tabular}



$80-89$
20.4
5.7
0 34
$90-100$
19.4
5.7
3
34

Have you attended BLS course previously?

$0.000^{\mathrm{a}}$

No

19.1

5.8

$21.6 \quad 4.8$

0

34

Yes

a: Independent-samples T test

b: One-way ANOVA

Table 3: CPR skills between those received BLS course and those who did not.

\begin{tabular}{lcccc}
\hline & $\begin{array}{c}\text { Received training n } \\
(\%)\end{array}$ & $\begin{array}{c}\text { Did not Receive training } \\
\mathbf{n}(\%)\end{array}$ & Total n (\%) & $\begin{array}{c}\text { P- } \\
\text { value }^{\text {a }}\end{array}$ \\
\hline Massage rate & $248(54.1 \%)$ & $618(37.3 \%)$ & $866(41 \%)$ & 0.000 \\
Massage location & $397(86.7 \%)$ & $1112(67.1 \%)$ & 1509 & 0.000 \\
& & & $(71.4 \%)$ & \\
Massage depth & $293(64 \%)$ & $794(47.9 \%)$ & 1087 & 0.000 \\
& & & $(51.4 \%)$ & \\
Massage/ventilation & $378(82.5 \%)$ & $838(50.6 \%)$ & 1216 & 0.000 \\
ratio & & & $(57.5 \%)$ & \\
\hline
\end{tabular}

a: chi-squared

Table 4: Perception of the medical students toward BLS. 


\begin{tabular}{|c|c|c|}
\hline \multicolumn{3}{|c|}{ Am I sure I can perform CPR by myself when required } \\
\hline Strongly disagree & 245 & $11.6 \%$ \\
\hline Disagree & 519 & $24.6 \%$ \\
\hline Neutral & 564 & $26.7 \%$ \\
\hline Agree & 684 & $32.4 \%$ \\
\hline Strongly agree & 102 & $4.8 \%$ \\
\hline \multicolumn{3}{|c|}{ Should people outside the medical field be taught CPR? } \\
\hline Strongly disagree & 55 & $2.6 \%$ \\
\hline Disagree & 138 & $6.5 \%$ \\
\hline Neutral & 250 & $11.8 \%$ \\
\hline Agree & 1092 & $51.7 \%$ \\
\hline Strongly agree & 579 & $27.4 \%$ \\
\hline
\end{tabular}

Basic life support education must be applied during the first and second year of the university

\begin{tabular}{lcc} 
Strongly disagree & 47 & $2.2 \%$ \\
\hline Disagree & 137 & $6.5 \%$ \\
\hline Neutral & 179 & $8.5 \%$ \\
\hline Agree & 1003 & $47.4 \%$ \\
\hline Strongly agree & 748 & $35.4 \%$
\end{tabular}

What is your self-assessment of mastery of Basic Life Support out of ten

$\begin{array}{lcc}5 \text { or less } & 1249 & 59.1 \% \\ 6 \text { or more } & 865 & 40.9 \%\end{array}$

How would you be if you came across someone in need of CPR?

\begin{tabular}{lcc} 
Not comfortable & 1487 & $70.3 \%$ \\
\hline Comfortable & 493 & $23.3 \%$ \\
\hline Avoid the situation & 134 & $6.3 \%$
\end{tabular}

Table 5: The top ten universities according to mean score.

\begin{tabular}{lcc}
\hline Top 10 & Mean & Country \\
\hline Al- Balqa' Applied University & 26.39 & Jordan \\
Hashemite University & 25.83 & Jordan \\
\hline Yarmouk University & 25.05 & Jordan \\
\hline Jordan University of Science and Technology & 23.57 & Jordan \\
\hline Mutah University & 23.4 & Jordan \\
\hline University of Jordan & 21.71 & Jordan \\
\hline University of Thi-Qar & 21.09 & Iraq \\
\hline University of Al-Qadisiyah & 20.89 & Iraq \\
\hline University of Baghdad & 20.78 & Iraq \\
\hline Hama University & 20.23 & Syria \\
\hline
\end{tabular}




\section{Figures}

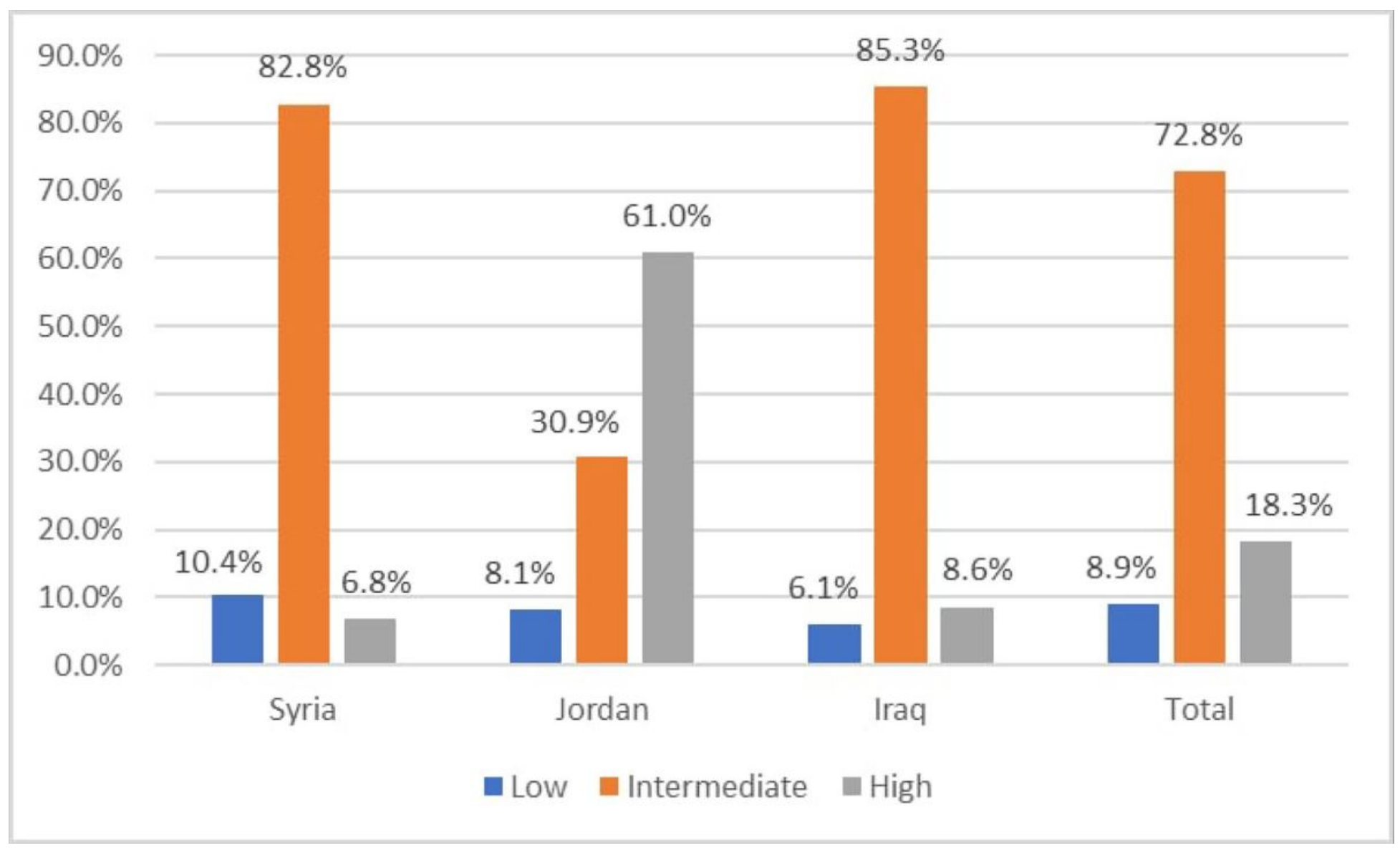

\section{Figure 1}

The percentage of the participant according to score's level.

\section{Supplementary Files}

This is a list of supplementary files associated with this preprint. Click to download.

- STROBEchecklistcrosssectional.docx

- additionalfile1.pdf 